Palavras chave: Vaporização de tábuas Defeitos de secagem

Taxa de secagem Eucalyptus

Histórico: Recebido 01/06/2012 Aceito 01/04/2014

Keywords: Boards steaming Drying defects Drying rate Eucalyptus

Correspondência: raphaelfloresta@hotmail.com
Raphael Nogueira Rezende', José Tarcísio Lima², Luana Elís de Ramos e Paula ${ }^{3}$, José Reinaldo Moreira da Silva ${ }^{2}$

\section{EFEITO DA VAPORIZAÇÃO NA SECAGEM DE TÁBUAS DE Eucalyptus grandis}

RESUMO: Neste trabalho, objetivou-se avaliar o efeito da vaporização na taxa de secagem e na qualidade da secagem de tábuas de Eucalyptus grandis. Para isso, utilizou-se uma madeira proveniente de um plantio da Universidade Federal de Lavras, MG, Brasil, com idade de 24 anos. Árvores foram abatidas e suas toras foram desdobradas por um sistema de corte tangencial. Dividiu-se a carga de tábuas à metade, sendo uma delas para secagem com vaporização e outra sem vaporização. Na secagem com vaporização, após a fase de aquecimento, houve um tratamento de 3 horas a $90^{\circ} \mathrm{C}$ e $100 \%$ de umidade relativa. A secagem ocorreu em estufa de secagem convencional e foram realizadas medições de defeitos e determinação da taxa de secagem. Os resultados indicaram que a vaporização foi eficiente, aumentando a taxa de secagem em $15 \%$ e reduzindo defeitos de secagem de 20 a $52 \%$.

\section{EFFECT OF THE STEAMING ON THE DRYING OF Eucalyptus grandis BOARDS}

ABSTRACT: The objective of this work was to evaluate the effect of the steaming on the drying rate and drying quality of Eucalyptus grandis boards. For this purpose, wood from an experimental plantation of the Federal University of Lavras, Minas Gerais State, Brazil, with 24 years of age was used. Trees were felled and sectioned in logs and the logs were sawn by a tangential system. Half of the boards volume were steamed during 3 hours at $90^{\circ} \mathrm{C}$ of temperature and $100 \%$ of relative humidity after the heating of the drying process. The other half was not steamed (control). The boards were dried in the dry-kiln and the resulting defects from the drying process and drying rate were determined. The results indicated that the steaming was effective in increase of the drying rate in $15 \%$ and decrease of the drying defects of 20 to $52 \%$. 


\section{INTRODUÇÃO}

A secagem da madeira é uma das etapas do processamento de madeira sólida responsável por melhor agregar valor ao produto final. De grande importância, é um processo que proporciona, entre outros benefícios, redução de massa, redução dos custos de transporte e de manuseio, aumento da resistência mecânica e redução da instabilidade dimensional da madeira (MARTINS, 1988).

Como qualquer etapa do processamento, a secagem deve ser conduzida de forma racional e criteriosa, a fim de se obter produtos competitivos e com considerável padrão de qualidade. Para Galvão e Jankowski (1985), os cuidados devem ser ainda maiores quando se trabalha com madeira pouco permeável, já que maior também é a sua propensão ao aparecimento de defeitos de secagem.

Madeiras do gênero Eucalyptus podem ser consideradas como de secagem lenta, difícil e complexa, em razão principalmente, da baixa permeabilidade, a qual é responsável por um acentuado gradiente de umidade, elevadas contrações, alta suscetibilidade ao colapso e às rachaduras e altas tensões de secagem (BARBOSA, 2003; CALONEGO; SEVERO, 2004; VERMAAS, 1995).

Além da baixa permeabilidade e da constituição anatômica peculiar, como pontoações de pequeno diâmetro, tiloses, baixa frequência e pequena largura de vasos e pequena largura de raios, a manifestação de tensões de crescimento contribui para uma maior propensão ao aparecimento de defeitos, tornando a secagem da madeira de Eucalyptus ainda mais complexa (CALONEGO et al., 2006).

Severo e Tomaselli (200I) afirmam que uma meta comum nas pesquisas sobre secagem de Eucalyptus é reduzir os tempos e custos de secagem e aumentar a qualidade da madeira seca. Para isso, um grande número de pré-tratamentos tem sido testados na tentativa de aumentar a permeabilidade e a taxa de secagem e reduzir o tempo do processo. Utilizando-se técnicas e condições apropriadas, é possível minimizar os defeitos e reduzir as perdas em volume de madeira que aumentam os custos do produto final (MARTINS et al., 200I). Além de adotar programas de secagem suaves, que utilizam baixas temperaturas e altas umidades relativas até completa remoção de água livre, técnicas complementares são requeridas, com o emprego de pré-tratamentos de secagem (SANTOS, 2002).

Severo (2004), Simpson (199I) e Vermaas (1995) afirmam que a secagem em estufa da madeira de Eucalyptus deve iniciar e se manter com temperaturas inferiores a $45^{\circ} \mathrm{C}$ até a completa remoção de água livre.
No entanto, o emprego desses programas de secagem considerados suaves aumenta o tempo de secagem e onera o processo produtivo. Assim, tratamentos preliminares à secagem se tornam mais atrativos e podem ser eficientes na minimização de alguns problemas da secagem da madeira de Eucalyptus.

Glossop (1994) afirma que a aplicação de tratamentos na madeira antes da secagem é uma forma de reduzir os tempos de secagem, bem como melhorar a qualidade da madeira. Substituição da água da madeira por líquidos orgânicos, congelamento, imersão em água quente e vaporização são alguns exemplos de prétratamentos e são considerados formas de facilitar a secagem da madeira (SIAU, 197I; VERMAAS, 1995).

$A$ vaporização é uma técnica que consiste na aplicação de vapor aquecido a altas temperaturas e umidades relativas por determinado tempo na madeira. Dentre seus propósitos pode-se citar a redução dos níveis de tensões de crescimento, esterilização da madeira, aumento da permeabilidade, redução da instabilidade dimensional, redução do teor de umidade inicial antes da secagem propriamente dita, redução dos gradientes de umidade, redução do tempo de secagem e aumento da taxa de secagem (CALONEGO; SEVERO, 2007; CHAFE, 1992). Em contraposição, sua aplicação pode implicar em alto custo energético e alterar a cor da madeira, embora a mudança de cor possa ser um aspecto positivo sob um ponto de vista estético e de agregação de valor dependendo do uso da madeira.

Os benefícios da técnica são garantidos pelos seus possíveis efeitos na madeira. Com a aplicação de vapor aquecido há uma facilitação do fluxo em função do aumento da temperatura da madeira e aumento do coeficiente de difusão (CHOONG et al., 1999). Kininmonth (I97I) afirma que a vaporização promove uma hidrolização parcial da membrana das pontoações, o que resulta em um aumento da permeabilidade. Para Diaz-Vaz et al. ( 1998), com a modificação na estrutura da membrana das pontoações, há uma dilatação e facilitação da remoção de água durante a secagem.

Aguiar e Perré (2005) consideram que, com a técnica, os polímeros amorfos da madeira atingem temperaturas de transição vítrea, tornando-os mais fluidos e flexíveis. Com o amolecimento da estrutura física da madeira, decorrente de maior fluidez molecular há um alívio de tensões internas, o que possibilita reduzir os níveis de defeitos de secagem (CALONEGO; SEVERO, 2005). Apesar dos benefícios e da proposição atual da técnica para diferentes espécies, ainda não há um consenso sobre a duração, o momento de aplicação e as condições do tratamento para cada espécie. 
Alexiou et al. (1990), por exemplo, mencionam um tratamento de vaporização a $100^{\circ} \mathrm{C}$, durante 3 horas, após I hora do aquecimento inicial para a redução de defeitos de secagem e aumento da taxa de secagem da madeira de Eucalyptus pilularis.

Em um estudo com pré-vaporização de tábuas de Eucalyptus dunnii, Severo (2000) adotou uma condição de vapor aquecido a $100^{\circ} \mathrm{C}$ e $100 \%$ de umidade relativa durante 3 horas, empregado antes da fase de aquecimento de um programa de secagem suave. Constatou-se uma redução média no índice de defeitos de colapso e de, encanoamento, na ordem de $60 \%$, enquanto para rachaduras a redução foi de $84 \%$.

Calonego et al. (2006), estudando o emprego de vapor aquecido a $90^{\circ} \mathrm{C}$ e $100 \%$ de umidade relativa, durante 3 horas, após I hora de aquecimento em secagem convencional da madeira de Eucalyptus grandis, constataram que o tratamento promoveu uma redução média de $38 \%$ no índice de rachaduras de topo e $30 \%$ no empenamento longitudinal.

Nesse contexto, com este trabalho, objetivou-se avaliar o efeito da vaporização na velocidade de secagem e na qualidade de tábuas secas de Eucalyptus grandis.

\section{MATERIAL E MÉTODOS}

Para a realização desse estudo, utilizou-se uma madeira proveniente de um plantio experimental pertencente à Universidade Federal de Lavras (UFLA), no município de Lavras, MG.

Quatro árvores de Eucalyptus grandis, com idade de 24 anos e plantadas em um espaçamento de $3,0 \times 2,0 \mathrm{~m}$ foram selecionadas ao acaso, abatidas e seccionadas em toras com $3,40 \mathrm{~m}$ de comprimento. As toras foram identificadas e conduzidas à Unidade Experimental de Desdobro e Secagem da Madeira (UEDSM), do DCF/UFLA, sendo na sequência destopadas. Em cada extremidade da tora, foi retirado um disco com $3,0 \mathrm{~cm}$ de espessura e este foi seccionado em cunhas, sendo duas cunhas opostas para a determinação da densidade básica, conforme a Norma NBRI I 94I/2003, da Associação Brasileira de Normas Técnicas - ABNT (2003).

Toras com diâmetro mínimo de $20 \mathrm{~cm}$ e comprimento médio de $340 \mathrm{~cm}$ foram escolhidas. Metade da carga foi destinada para uma secagem com tratamento de vapor aquecido e o restante para uma secagem sem vaporização (testemunha). $O$ desdobro das toras foi realizado em uma serra de fita simples, por meio de cortes sucessivos e paralelos (desdobro tangencial), de acordo com recomendações de Ferreira et al. (2004). As tábuas foram medidas com auxílio de um paquímetro digital de precisão $0,01 \mathrm{~mm}$, apresentando dimensões nominais de $3,0 \mathrm{~cm}$ de espessura, largura variável em função do diâmetro das toras e $300 \mathrm{~cm}$ de comprimento (igual ao comprimento das toras).

A secagem da madeira foi realizada em uma estufa de secagem convencional da UEDSM do DCF/UFLA, com capacidade aproximada para $2 \mathrm{~m}^{3}$ de madeira serrada e dotada de 4 sensores de umidade. As tábuas foram empilhadas e entabicadas, utilizando-se separadores de $25 \mathrm{~mm}$ de espessura. A fim de se minimizar defeitos nas tábuas das camadas superiores, foram colocadas placas de concreto de $50 \mathrm{~kg}$ sobre mesmas.

A fim de se obter um acompanhamento mais preciso em cada processo de secagem, quatro amostras de controle e oito determinadoras de umidade foram obtidas, sendo as de controle posicionadas nas pilhas para obtenção da perda de umidade e velocidade de secagem. Admitiu-se a umidade média de duas amostras determinadoras de uma mesma tábua como a umidade inicial da amostra controle, conforme metodologia adotada por Rasmussen (196I). A massa seca foi estimada diretamente, a partir da massa inicial e da umidade inicial da amostra de controle. Para a determinação da umidade, seguiram-se as recomendações da Norma NBRI 194I/2003, da ABNT (2003). As amostras de controle foram posicionadas em diferentes camadas da pilha, de acordo com recomendações do fabricante da estufa. De posse dos dados de umidade, ao longo do tempo, foi possível obter curvas de secagem do tipo "umidade $x$ tempo" e taxas de secagem em \% de umidade $\cdot \mathrm{dia}^{-1}$.

O programa de secagem utilizado neste estudo baseou-se no sugerido por Santos (2002), para tábuas de Eucalyptus grandis, com até $40 \mathrm{~mm}$ de espessura, com uma adaptação para a umidade final de 12\% (Tabela 1). A primeira carga de tábuas foi submetida ao programa de secagem com tratamento de vaporização adaptado de Calonego et al. (2006); aplicou-se vapor a $90^{\circ} \mathrm{C}$ e $100 \%$ de umidade relativa durante 3 horas, após a fase completa de aquecimento. A segunda carga de tábuas foi submetida ao programa de secagem sem a aplicação do tratamento.

A avaliação da qualidade da madeira seca foi realizada ao fim de cada processo de secagem por meio de uma análise de defeitos nas tábuas. Foram avaliados os seguintes defeitos: rachaduras de topo, arqueamento, encanoamento, encurvamento, torcimento e colapso. 
TABELA 1 Programa de secagem para tábuas de Eucalyptus grandis com até $40 \mathrm{~mm}$ de espessura com adaptação de umidade final.

TABLE 1 Drying schedule for up to $40 \mathrm{~mm}$ thick lumber of Eucalyptus grandis with adaptation of final moisture content.

\begin{tabular}{ccccc}
\hline Fase & $\begin{array}{c}\text { Umidade da } \\
\text { madeira } \% / \\
\text { tempo }(\mathrm{h})\end{array}$ & $\begin{array}{c}\text { TBS } \\
\left({ }^{\circ} \mathrm{C}\right)\end{array}$ & $\begin{array}{c}\text { TBU } \\
\left({ }^{\circ} \mathrm{C}\right)\end{array}$ & $\begin{array}{c}\text { UR } \\
(\%)\end{array}$ \\
\hline Aquecimento & $6 \mathrm{~h}$ & 40 & 38 & 88 \\
Secagem 1.1 & $>50$ & 40 & 38 & 88 \\
Secagem 1.2 & 45 & 40 & 38 & 88 \\
Secagem 1.3 & 40 & 40 & 37 & 85 \\
Secagem 1.4 & 35 & 40 & 37 & 85 \\
Secagem 1.5 & 30 & 40 & 36 & 77 \\
Secagem 1.6 & 25 & 51 & 45 & 72 \\
Secagem 1.7 & 20 & 57 & 49 & 62 \\
Secagem 1.8 & 15 & 65 & 52 & 50 \\
Secagem 1.9 & 12 & 65 & 52 & 50 \\
Uniformização & 12 & 65 & 58 & 68 \\
Condicionamento & 14 & 66 & 62 & 82 \\
\hline
\end{tabular}

Os índices de colapso foram obtidos conforme a metodologia de Barbosa et al. (2005), que se baseia na variação de espessura normal e deformada das tábuas e, também, na relação entre área de topo normal e área de topo deformada, obtidas em software de análise de imagens. A classificação do índice de colapso foi adaptada, considerando-se colapso ausente para um índice igual a I,0; colapso leve para índices entre 0,95 e I,0; colapso médio para índices entre 0,90 e 0,95 e colapso forte para índices inferiores a 0,90.

Os índices de rachaduras e empenamentos diversos foram determinados conforme a Norma Brasileira para Classificação de Madeira Serrada de Folhosas (BRASIL, 1983).

A avaliação dos resultados foi realizada por meio de uma análise de variância e um teste de Tukey, a um nível de significância de 5\%, considerando-se um delineamento inteiramente casualizado, a fim de se avaliar as diferenças entre os defeitos de secagem e as taxas de secagem dos processos com e sem tratamento de vaporização.

A análise estatística da variação de umidade em função do número de dias de secagem para os processos com e sem vaporização correspondeu a um ajuste de regressão, considerando-se um modelo exponencial e um nível de probabilidade de erro de $5 \%(\alpha=0,05)$. Os ajustes foram realizados em software estatístico, obtendose para cada ajuste o coeficiente de determinação $\left(R^{2}\right)$.

\section{RESULTADOS E DISCUSSÃO}

A densidade básica da madeira apresentou média de $0,553 \mathrm{~g} \cdot \mathrm{cm}^{-3}$, próxima a valores encontrados na literatura. Para uma madeira de Eucalyptus grandis, com 25 anos de idade, e desenvolvendo-se na mesma região objeto deste estudo, Rezende et al. (2010) obtiveram valores entre 0,525 e $0,542 \mathrm{~g} \cdot \mathrm{cm}^{-3}$.

As curvas de secagem ajustadas para as tábuas de Eucalyptus grandis, com e sem, a aplicação do tratamento de vaporização, estão apresentadas na Figura 1.

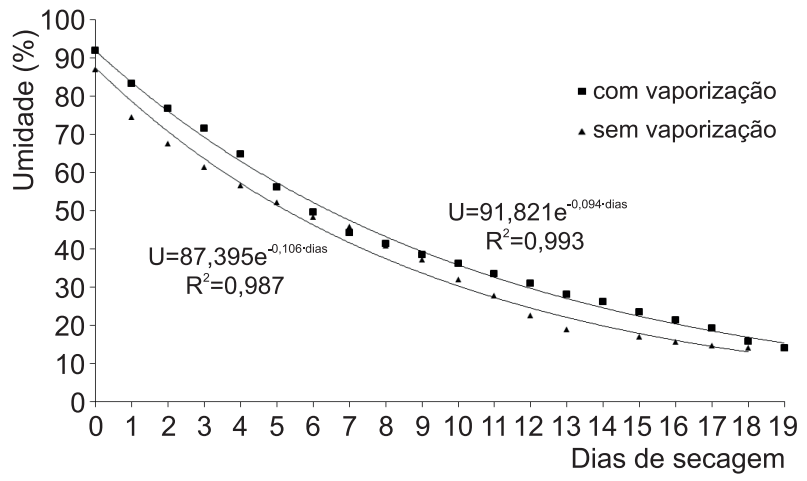

FIGURA 1 Curvas de secagem ajustadas de tábuas de Eucalyptus grandis com e sem tratamento de vaporização.

FIGURE 1 Fitted drying curves for Eucalyptus grandis boards with and without steaming treatment.

No processo de secagem com vaporização, as tábuas apresentaram, após o aquecimento inicial, um ganho médio de $9 \%$ de umidade em relação à umidade inicial, mas que reduziu, sensivelmente, no primeiro dia secagem. Esse aumento não foi representado na curva de secagem, por ser aplicado, anteriormente, ao processo de secagem propriamente dito, mas foi contabilizado para os cálculos de velocidade de secagem. Para a curva de secagem sem vaporização, não houve esse ganho em relação à umidade inicial (87\%) por não haver tratamento com vapor aquecido e úmido. A partir da análise das curvas de secagem, observou-se para as tábuas vaporizadas uma redução total de umidade de $87 \%$, durante 19 dias de secagem, partindo-se de uma umidade inicial de $92 \%$, com um aumento de $9 \%$ após a vaporização e finalização da secagem com umidade média das tábuas de 14\%. Para as tábuas não vaporizadas, a redução total foi de $73 \%$, durante 18 dias, com base em uma umidade inicial de $87 \%$ e final de $14 \%$. As maiores perdas de umidade foram observadas nos cinco primeiros dias de secagem, condizendo às observações de Santos et 
al. (2003). Esses autores observaram para a secagem de tábuas de Eucalyptus grandis maiores taxas no início da secagem, com a taxa decrescendo com o tempo, à medida que diminui o teor de umidade. As durações dos processos de secagem com e sem vaporização foram diferentes. Dessa forma, a avaliação quantitativa e estatística da redução de umidade ao longo do tempo foi realizada com base na velocidade de secagem. Para os ajustes das curvas de secagem, os resultados foram satisfatórios, indicando que mais de $98 \%$ das variações de umidade em função do tempo foram explicadas pelo modelo exponencial.

Os resultados para a taxa média de secagem das tábuas com e sem vaporização estão apresentados na Tabela 2. Apesar do tempo de secagem das tábuas vaporizadas ter sido superior ao das não vaporizadas, 19 dias e 18 dias, respectivamente, as maiores velocidades foram observadas para as tábuas que receberam o tratamento.

TABELA 2 Taxa de secagem média de tábuas de Eucalyptus grandis vaporizadas e não vaporizadas.

TABLE 2 Average drying rate of Eucalyptus grandis boards with and without steaming treatment.

\begin{tabular}{|c|c|c|c|}
\hline \multirow{2}{*}{ Secagem } & \multicolumn{3}{|c|}{ Taxa de secagem $\left(\%\right.$. dia $\left.^{-1}\right)$} \\
\hline & Média & Mínima & Máxima \\
\hline Com vaporização & 4,6 a & 2,0 & 18 \\
\hline Sem vaporização & $4,0 \quad b$ & 0,5 & 13,0 \\
\hline
\end{tabular}

*Médias seguidas da mesma letra na coluna não diferem entre si pelo Teste de Tukey em nível de $5 \%$ de probabilidade de erro.

O tratamento de vaporização aumentou a taxa de secagem em torno de I5\%, passando de 4,0\% (testemunha) para 4,6\% ao dia. Esses resultados estão de acordo com as observações de Alexiou et al. (1990), que obtiveram para tábuas de Eucalyptus pilularis submetidas a 3 horas de vaporização $\left(100^{\circ} \mathrm{C}\right)$ um aumento da taxa de 7 a 16\%. De acordo com esses autores, uma das prováveis explicações para o aumento da taxa de secagem é a remoção de alguns extrativos e aumento do coeficiente da difusão. Choong et al. (1999) também constataram efeitos positivos da vaporização para o aumento da taxa de secagem, ressaltando as explicações de Alexiou et al. (1990). Santini e Haselein (2002) consideram ainda que o emprego da alta temperatura resulta em um aumento da taxa de transferência de calor para madeira, o que, consequentemente, eleva as taxas de secagem.

Os resultados obtidos para os defeitos de secagem (qualidade da secagem) de tábuas vaporizadas e não vaporizadas estão apresentados na Tabela 3. Como esperado, observou-se que a vaporização reduziu os defeitos de secagem. Essa redução pode ser explicada pelo alívio de tensões internas em razão do amolecimento da estrutura física da madeira submetida ao vapor aquecido e úmido (AGUIAR; PERRÉ, 2005; CALONEGO; SEVERO, 2005). Embora tenha sido utilizado um programa de secagem com baixa temperatura inicial $\left(40^{\circ} \mathrm{C}\right)$, o colapso foi observado em tábuas vaporizadas e não vaporizadas. Para Barbosa et al. (2005) e Bariska (1992), mesmo empregando-se baixas temperaturas, a madeira do gênero Eucalyptus tem alta propensão ao colapso, em razão, principalmente, da sua baixa permeabilidade.

TABELA 3 Defeitos de secagem de tábuas de Eucalyptus grandis vaporizadas e não vaporizadas.

TABLE 3 Drying defects of Eucalyptus grandis for untreated and steamed boards.

\begin{tabular}{lcc}
\hline \multirow{2}{*}{ Defeito de secagem } & \multicolumn{2}{c}{ Secagem } \\
\cline { 2 - 3 } & $\begin{array}{c}\text { Sem } \\
\text { vaporização }\end{array}$ & $\begin{array}{c}\text { Com } \\
\text { vaporização }\end{array}$ \\
\hline Rachadura de topo (\%) & $12,10 \mathrm{a}$ & $9,70 \mathrm{~b}$ \\
Arqueamento (\%) & $0,28 \mathrm{a}$ & $0,19 \mathrm{~b}$ \\
Encurvamento (\%) & $0,22 \mathrm{a}$ & $0,10 \mathrm{~b}$ \\
Encanoamento (\%) & $0,33 \mathrm{a}$ & $0,17 \mathrm{~b}$ \\
\hline Colapso & \\
\hline Variação de espessura (mm) & $4,70 \mathrm{a}$ \\
Índice de colapso & $0,83 \mathrm{a}$ & $3,50 \mathrm{~b}$ \\
Classificação & Forte & Leve \\
\hline
\end{tabular}

*Médias seguidas da mesma letra na linha não diferem entre si pelo Teste de Tukey ao nível de $5 \%$ de probabilidade de erro.

A partir da Tabela 3, observa-se que a redução dos defeitos foi significativa com o emprego da técnica. Para o índice de rachaduras de topo, houve uma redução de aproximadamente $20 \%$, redução esta de acordo com o intervalo de resultados de literatura. Alexiou et al. (1990) e Calonego et al. (2006) obtiveram reduções de 30 a $50 \%$ nos índices de rachadura de topo com a aplicação da vaporização de tábuas. Para os índices de arqueamento, encurvamento e encanoamento as reduções foram em torno de 20, 52 e 50\%, respectivamente. Souza et al. (2012) constataram para tábuas de Eucalyptus grandis, aos 14 anos de idade, índices médios de rachaduras de topo e de arqueamento, variando de $15, \mathrm{I}$ a $23,7 \%$ e de 0,34 a $0,41 \%$, respectivamente, valores esses superiores aos obtidos no estudo.

A vaporização não foi capaz de eliminar o colapso, mas foi efetiva na redução desse defeito, que segundo Mackay (197I), pode ser explicado pelo aumento da permeabilidade do material, que facilita a 
retirada da água livre e diminui a ocorrência do defeito. Com o emprego do tratamento, a variação entre espessura normal e colapsada de tábuas apresentou um decréscimo médio de $25 \%$. O índice de colapso também foi sensivelmente reduzido, passando de forte $(0,83)$ para leve $(0,95)$ com a vaporização. Esse índice para tábuas vaporizadas $(0,95)$ está próximo ao índice de colapso obtido por Baraúna (2007). Trabalhando com tábuas de Eucalyptus grandis submetidas a um programa de secagem suave por desumidificação, com temperaturas inferiores a $30^{\circ} \mathrm{C}$, o mesmo autor obteve um índice médio de colapso de 0,96 . Pode-se dizer, então, mesmo utilizando-se um programa de secagem convencional, a técnica de vaporização, deste estudo, teve um efeito semelhante ao de uma secagem por desumidificação na minimização do colapso.

\section{CONCLUSÕES}

Com base nos resultados obtidos, pode-se concluir que: a vaporização foi eficiente para o aumento da taxa de secagem e melhoria da qualidade da secagem; o emprego da técnica promoveu um aumento médio de $15 \%$ na taxa de secagem das tábuas; e os índices de defeitos de secagem foram significativamente reduzidos com o tratamento, variando de 20 a $52 \%$.

\section{AGRADECIMENTOS}

À CAPES, ao CNPq e à FAPEMIG pelo apoio financeiro concedido ao desenvolvimento deste trabalho (Processo: CAGAPQ-488I-3.10/07).

\section{REFERÊNCIAS}

AGUIAR, O. J. R.; PERRÉ, P. Wood accelerating drying process based on its rheological properties. US $n$. 6910284B2, 28 jun. 2005.

ALEXIOU, P. N.; WILKINS, A. P.; HARTLEY, J. Effect of presteaming on drying rate, wood anatomy and shrinkage of regrowth Eucalyptus pilularis Sm. Wood Science and Technology, Berlin, v. 24, n. I, p. 103110,1990

ASSOCIAÇÃO BRASILEIRA DE NORMAS TÉCNICAS. NBR I | 94 I: madeira: determinação da densidade básica. Rio de Janeiro, 2003. 6 p.

BARAÚNA, E. E. P. Estufa para secagem de madeira por desumidificação: projeto e construção. Lavras: UFLA, 2007. $44 \mathrm{p}$.
BARBOSA, C. G. Incidência dos defeitos de secagem como índice de qualidade e de seleção genética para madeira de Eucalyptus. 2003. 7I p. Dissertação (Mestrado em Engenharia Florestal) - Universidade Federal de Lavras, Lavras, 2003.

BARBOSA, C. G.; LIMA, J. T.; ROSADO, S. C. S.; TRUGILHO, P. F. Elaboração de programa de secagem para madeiras de clones de híbridos de Eucalyptus spp. Cerne, Lavras, v. I I, n. I, p. 40-48, jan./jun. 2005.

BARISKA, M. Collapse phenomena in eucalypts. Wood Science and Technology, Berlin, v. 26, n. 3, p. 165-179, 1992.

BRASIL. Ministério da Agricultura. Instituto Brasileiro de Desenvolvimento Florestal. Norma para classificação de madeira serrada de folhosas. Brasília, 1983. 67 p.

CALONEGO, F. W.; SEVERO, E. T. D. Efeito da vaporização de toras na redução dos defeitos associados a tensões de crescimento de Eucalyptus grandis. Ciência Florestal, Santa Maria, v. I5, n. 4, p. 43I-440, out. 2005.

CALONEGO, F. W.; SEVERO, E. T. D. Efeito da vaporização de toras na secagem da madeira de Eucalyptus grandis. Floresta e Ambiente, Rio de Janeiro, v. I I, n. I, p. 7-I3, ago./dez. 2004.

CALONEGO, F. W.; SEVERO, E. T. D. Influência da posição diametral das tábuas e da vaporização nos defeitos de secagem de Eucalyptus grandis. Cerne, Lavras, v. I3, n. I, p. I0-I8, jan./mar. 2007.

CALONEGO, F. W.; SEVERO, E. T. D.; CONEGLIAN, A.; BARREIROS, R. M. Qualidade da secagem de Eucalyptus grandis mediante vaporização simultânea em toros e em madeira serrada. Silva Lusitana, Lisboa, v. I4, n. 2, p. I68I80, 2006.

CHAFE, S. C. Changes in shrinkage, collapse and green volume in the wood of Eucalyptus regnans $\mathrm{F}$. Muell after heating in water. Wood Science and Technology, Berlin, v. I2, n. 6, p. 34I-345, 1992.

CHOONG, E. T.; SHUPE, T. F.; CHEN, Y. Effect of steaming and hot-water soaking on extractive distribution and moisture diffusivity in southern pine during drying. Wood and Fiber Science, Madison, v. 3I, n. 2, p. I43-I50, Apr. 1999.

DIAZ-VAZ, J. E.; POBLETE, H.; SCHIMIT, U. Water immersion pretreatment of Eucalyptus wood. Holzforschung, Berlin, v. 50, n. 5, p. 85-88, 1998.

FERREIRA, S.; LIMA, J. T.; ROSADO, S. C. S.; TRUGILHO, P. F. Influência de método de desdobro tangenciais no rendimento e na qualidade da madeira de clones Eucalyptus spp. Cerne, Lavras, v. I0, n. I, p. I0-2I, jan./jun. 2004.

GALVÃO, A. P. M.; JANKOWSKY, I. P. Secagem racional da madeira. São Paulo: Nobel, 1985. II I p. 
GLOSSOP, B. R. Effect of hot-water soaking or freezing pretreatments on drying rates of two eucalypts. Forest Products Journal, Madison, v. 44, n. 10, p. 29-32, 1994.

KININMONTH, J. A. Permeability and fine structure of certain hardwoods and effects on drying: I., transverse permeability of wood to micro-filtered water. Holzforschung, Berlin, v. 25 , n. 4, p. 127-133, 1971 .

MACKAY, J. F. G. Influence of steaming on water vapor diffusion in hardwoods. Wood Science, Madison, v. 3, n. 2, p. I56160, 1971.

MARTINS, V. A. Secagem de madeira serrada. Brasília: IBDF, 1988. $56 \mathrm{p}$.

MARTINS, V. A.; GOUVEIA, F. N.; MARTINEZ, S. Secagem convencional de madeira de eucalipto parte I: Eucalyptus cloeziana F. Muell, E. grandis Hil Ex Maiden e E. pilularis Sm. Brasil Florestal, Piracicaba, n. 70, p. 42-47, jul. 2001.

RASMUSSEN, E. F. Dry kiln operator's manual. Madison: USDA, 196I. I88 p.

REZENDE, R. N.; LIMA, J. T.; PAULA, L. E. R.; FARIA, A. L. R. Secagem ao ar livre de toras de Eucalyptus grandis em Lavras, MG. Cerne, Lavras, v. I6, p. 4I-47, jul. 20I0. Suplemento.

SANTINI, E. J.; HASELEIN, C. R. Efeito da temperatura e velocidade do ar sobre a taxa de secagem da madeira de Pinus elliottii Engelm. Ciência Florestal, Santa Maria, v. 12, n. 2, p. 99-106, dez. 2002.

SANTOS, G. R. V. Otimização da secagem da madeira de Eucalyptus grandis Hill ex Maiden. 2002. 70 p. Dissertação (Mestrado em Ciência e Tecnologia da Madeira) - Escola Superior de Agricultura “Luiz de Queiroz”, Piracicaba, 2002.
SANTOS, G. R. V.; JANKOWSKI, I. P.; ANDRADE, A. Curva característica de secagem para madeira de Eucalyptus grandis. Scientia Forestalis, Piracicaba, n. 63, p. 214-220, jun. 2003.

SEVERO, E. T. D. Pré-vaporização: uma técnica para otimizar a secagem de madeira sólida de Eucalyptus grandis. 2004. 85 p. Tese (Livre Docência em Secagem da Madeira) - Universidade Estadual Paulista, Botucatu, 2004.

SEVERO, E. T. D. Qualidade da secagem de madeira serrada de Eucalyptus dunnii. Ciência Florestal, Santa Maria, v. I0, n. I, p. 109-124, 2000.

SEVERO, E. T. D.; TOMASELLI, I. Efeito da pré-vaporização em algumas propriedades físicas da madeira de Eucalyptus dunnii. Cerne, Lavras, v. 7, n. 2, p. 35-42, 2001.

SIAU, J. F. Flow in wood. Syracuse: Syracuse University, I97I. I3I p.

SIMPSON, W. T. Dry kiln operator s manual. Madison: USDA, 1991. $274 \mathrm{p}$.

SOUZA, J. T.; TREVISAN, R.; DENARDI, L.; STANGERLIN, D. M.; VIVIAN, M. A.; HASELEIN, C. R.; SANTINI, E. J. Qualidade da madeira serrada proveniente de árvores dominantes e médias de Eucalyptus grandis submetidas à secagem. Cerne, Lavras, v. I8, n. I, p. I67-I74, jan./mar. 2012.

VERMAAS, H. F. Drying eucalypts for quality: material characteristics, pré-drying treatments, drying methods, schedules and optimization of drying quality. Suid Afrikaance Bosboutydskrif, Pretoria, n. 174, p. 4I-49, 1995. 